\title{
Mobile Assisted Vocabulary Learning: Examining the Effects on Students' Vocabulary Enhancement
}

\author{
Peremalatha Govindasamy ${ }^{1, *}$, Melor Md Yunus ${ }^{2}$, Harwati Hashim ${ }^{2}$ \\ ${ }^{1}$ SMK Saujana Impian, Kajang, Malaysia \\ ${ }^{2}$ Faculty of Education, National University of Malaysia, Malaysia
}

Received August 31, 2019; Revised November 24, 2019; Accepted December 3, 2019

\begin{abstract}
Copyright@2019 by authors, all rights reserved. Authors agree that this article remains permanently open access under the
\end{abstract} terms of the Creative Commons Attribution License 4.0 International License

\begin{abstract}
The use of mobile phones combined with internet has become so handy in the present world of science, information and communication technologies. The mobile learning strategies have created several new ways to assist learners in the progression of learning a second language. One of the most vital challenges that learners will face during the learning of a second language is knowing the meaning of a vocabulary in order to understand the idea of the sentence. Given the importance of knowing the meaning of vocabularies / words through mobile assisted learning, this study attempts to investigate the effectiveness of using Mobile Phone to search for the meaning of vocabulary compared to the conventional way of using a printed dictionary. Therefore, 50 form 5 arts stream pupils from a public school in a state of Malaysia were selected for an experimental study. A Pre-test and Post-Test of vocabulary have been performed to find out the effectiveness of using the mobile phone technology compared to the printed dictionary. The results of the experimental study clearly show that using mobile phones enhances the pupil's knowledge in learning and knowing the meaning of the vocabulary deeper compared to the printed dictionary. This is because the vocabulary can be found in the form of images and the pronunciation of the word can be listened and seen in the form of an audio or video. The use of mobile phones which combined with the internet, have led to an increase in the scores of the pupils and the search for the vocabulary can be done faster than the printed dictionary. In conclusion, mobile phone can be considered as a good pedagogical tool in learning English as the second language (ESL).
\end{abstract}

Keywords Mobile Assisted Vocabulary Learning, Mobile Phone, Dictionary, Technology, ESL

\section{Introduction}

The fast growth in Information Communication and
Technologies (ICT) currently created amazing changes in many fields and education is one of the major fields that needs reformation. It is difficult to imagine educational institutions without computers and internet access. The use of internet and computers has led to huge change in our lifestyles. The reformation of education is an enormous undertaking. It has to start with a clear idea what and how it has to be carried out to make an improvement that is practical in the real current world.

\subsection{The Malaysian Education System on English Language}

The National Education Philosophy which was written in 1988 and revised in 1996, aims at the holistic development of all children in producing intellectually, spiritually, emotionally and physically balanced individuals. In order to produce these individuals, our Malaysian Education Ministry came up with an excellent Malaysia Education Blueprint 2013-2025 (Preschool to Post- Secondary Education) (Malaysia, 2013). There are 6 key attributes needed for the children to be globally competitive. Every student will have knowledge, thinking skills, leadership skills, bilingual proficiency, national identity, ethics and spirituality which are very much aligned with our National Education Philosophy. The bilingual proficiency as one of the six key attributes; highlights on the child's proficient level in Bahasa Malaysia as the National Language which is also a language of unity and English as the international language of communication. The Ministry of Education expects all the students to be able to work in both languages; Bahasa Malaysia and English language environment, upon leaving school. This shows that English language has been given equal importance in our education curriculum. It is important for the students to learn English Language and score in their Public Examination in order to attain good results for the English Paper. Their English language result is important for their future because the result will be used as the proof on 
their achievement in the language. There are also 11 shifts of transformation in the Malaysia Education Blue print 20132025. The seventh shift mentions on the leverage ICT to scale up quality learning across Malaysia. There were few points highlighted here which are; providing internet access and virtual learning environment for all 10,000 schools, increasing online content to share best teaching practices and maximising the use of ICT for distance and self-paced learning. (Malaysia, 2013).

\subsection{The New ICT Transformation Plan (2019-2023)}

Recently, The Malaysian Education ministry ((KPM)., 2019) has come up with a new plan of transformation known as ICT Transformation Plan (ITP) for the ministry of Education, 2019-2023 with the idea of strengthening ICT delivery capability to support the education ecosystem. The ITP plan is a 5-year to transform the Education Ministry that accelerates the usage of ICT to support the overall education ecosystems. The ITP also intends to create opportunities for the Ministry to embed digital and innovation in operations which will give impact to all the personnel at the ministry, educators and students. The 5-year, Education lifecycle platform also includes Mobile App integration. In our public schools currently, mobile technology has been widely exposed to the teachers to get their administration work such as keying in attendance done as soon as the students reach the school. Besides that, there is big project connecting 10000 government schools in Malaysia which is known as "1 BestariNet Project” providing an online Virtual Learning Environment (VLE) enabling students to learn anywhere at any time. However, without the technology, mobile learning device and internet access, this will not be possible. (Frog VLE, 2019)

\subsection{Mobile Phone and Restrictions}

In this current situation, obtaining information is not a big deal with technology around us. One of the most used devices is mobile phone. Mobile phones have become a necessity in our lives and it has become the medium of communication. Nowadays mobile phone comes with the access to the internet as well because many deals and errands are done with just a touch on the screen. (Giselle Tsirulnik). In the current era, dictionary use via mobile devices has mostly been used for referential purposes. Referential use refers to how the students google for information that provides student with access to content such as dictionaries, Wikipedia, pictures, graphics, e-books, etc. at anytime and anywhere learning processes or activities occur. The portability and mobility of mobile devices which is handheld are so convenient for the learning purpose. Research on student using mobile devices such as hand phones in vocabulary learning in the Malaysian Public School remains scant, and no in-depth studies have been carried out to investigate the effectiveness of word search using the mobile phones for vocabulary learning among the form five students in the public schools. This could be due to the restriction of the circular issued on $25^{\text {th }}$ March 2009 - KP (BS-Dsr)201/002/1 Jld 2(2) by the Office of DirectorGeneral of Education Malaysia restricting the use of mobile phones in school.

Mobile phones will be the best tool to use in the learning process for the Upper Secondary Level students in our public schools because of its size and how this device can actually help the learners. This small size device can connect the students with many links for information. The size and the weight of the device is much smaller and lighter making it more convenient to be carried around and information be obtained faster compared to a printed material because much information is accessible on this device at anywhere and anytime as long as it is connected to the internet. The Education Ministry of Malaysia is really working on the accessibility to provide the internet access according to the Malaysia Education Blueprint 2013-2025 (Preschool to PostSecondary Education) and ICT Transformation Plan (ITP).

\section{Literature Review}

This section describes the literature review to the study. This section is divided into 3 sub sections which are (2.1) The Dale's Cone of experience (1969) and Mobile Phone as a tool in Learning Language, (2.2) A linguist prediction and (2.3) Past Studies on the Use of Technology and Mobile Learning.

\subsection{The Dale's Cone of Experience and Mobile Phone as a Tool in Learning Language}

The Dale's Cone of experience (1969) would be an appropriate Model that can be used to demonstrate the effectiveness of the Mobile phone usage in the learning of vocabulary meaning. 


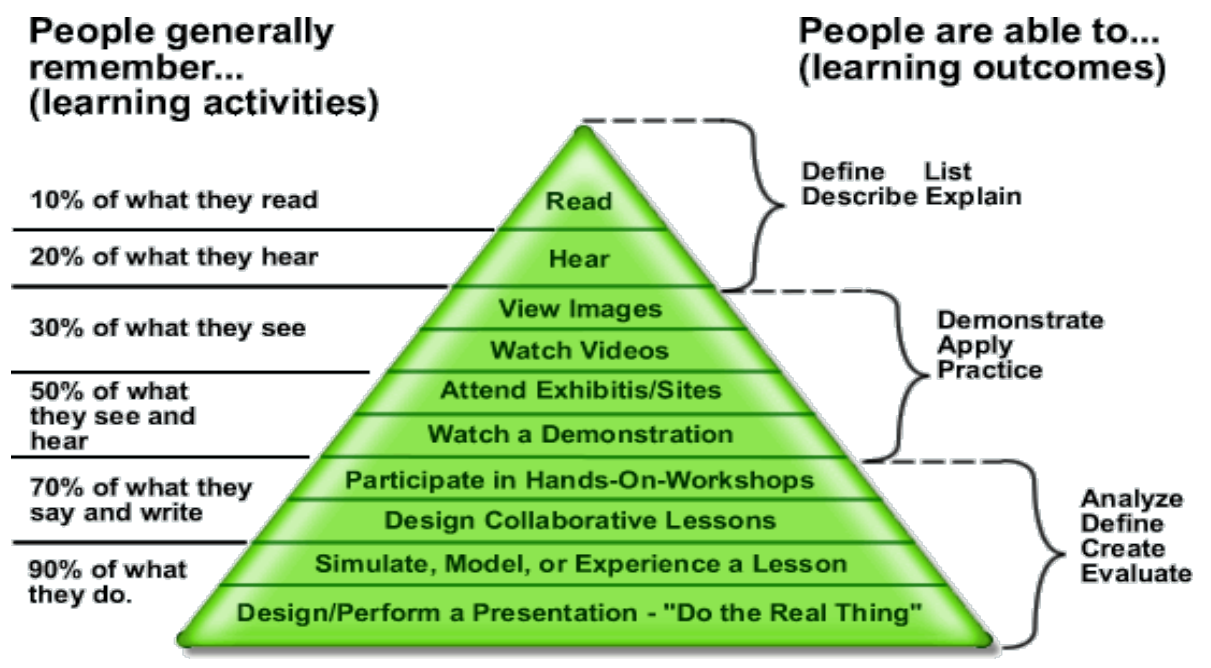

Figure 1. Cone of learning adapted from Dale's cone of experience (1969)

(Foundation, Cone of Experience - Edgar Dale (1969), 2018) Cone of experience research shows the most effective methods are at the very bottom. The more you progress downwards the more you strengthen the knowledge. In another word, the more you see, hear, participate in activities, present and express the idea, it will enhance the learning more. This can also be applicable to learn vocabulary and understand the meaning in its context. Therefore, this theory will be appropriate for the use of mobile phone as a learning tool to learn vocabulary. It will be applicable when the word is put as the subject of the learning. The final stage of the learning outcome is at the very bottom stage which enables the students to define a word on their own. The students use a different learning style to learn vocabulary by remembering what they see which is the image of the word; remembering what they hear which is the pronunciation of the word; and remembering what they write which is the spelling of the word and lastly to apply the word learnt whenever they get the chance to use the word in the their conversation. These enable the students to be more productive in knowing, learning and applying the word in the language which will lead them to perform better in their academic results and their daily language practice.

\subsection{A linguist Prediction}

(Krashen, 1989) says that you don't have to "live in the country” in order to achieve any real proficiency in acquiring a second language, and the informal actual environment is always superior compared to the formal environment because it supplies comprehensible input. He predicted that a set of materials aimed at language acquisition will encourage acquisition at the fastest possible rate. This "language acquisition device" may be so powerful in the future. Thus, he leaves this to the future enhancements. So, this is the future he would have probably predicted to help learners in acquiring the second language. In this case here, we can compare the 'chalk and talk' classroom, printed books method those days to the current strategies in language acquisition with the optimal use of the technology.

\subsection{Past Studies on the Use of Technology and Mobile Learning}

Many studies have been carried out on the Use of Technologies and Mobile Technologies for Learning a language.

(Dorothy Chun, 2016) stated that incorporating technology for language teachers into their teaching is important but also considers the consequences. This technology can be incorporated by considering and evaluating their suitability and the impact of the type of technology used. The technology should support specific learning goals. When the teachers and students use the technology wisely and purposefully, it will certainly engage them in some degree of critical reflection of their own learning as communication technologies these days that provide meaningful and useful resources for language learners to become aware of and actively reflect on communicative practices. It is important for the language learners and teachers to follow and know the current trend of technologies influence and also to consider the social consequences that might occur. This will be a key to adapting proficiency in a second language or a foreign language. Though this study mentioned on the consequences of a technology but it still supports the idea using technology appropriately to enhance the learning process.

(Maslawati M., 2014)indicated that the integration of Technology in language learning has profited students as they are not just learning in isolation, but are able to relate their learning to actual life situations

Another technology-based tool used in a current recent study is the infographics in an ESL context towards enhancing the $21^{\text {st }}$ century learning skills. This study (Fetylyana Nor Pazilah, 2018) stated that integrating infographics as a part of the visual aids in an ESL classroom 
will increase the motivation among the learners who are digital natives. It increases the learning interest to use the technology that they are very much into currently. It will also boost the $21^{\text {st }}$ century skills that are very much highlighted in this current education transformation.

Mobile Assisted Language Learning (MALL) is a method where language learning is enhanced or assisted through a handheld mobile device such as iPad, Tab, MP3, PDAs, mobile phone and etc. It provides global access to learning anywhere, anytime the user has the reception to the internet which enables users to improve on any language skills that they want to learn (Foundation, Mobile Assisted Language Learning (MALL), 2019). The use of MALL in a local private vocational college was conducted by (Wan Ummu Aiman Wan Azli, 2018) with positive results in enhancing the teaching and learning process. The study proves that MALL can be used as an effective pedagogical method to teach the second language such as English. The study recommends the stake holders such as curriculum designers and educators to use the mobile phone as a tool of learning because it is more interactive and learners are more independent.

(Harwati Hashim, 2017) stated that learning English as Second language using the mobile technology will enhance the teaching and learning. The portability of the device allows the learners to learn at anytime and anywhere. The mobile devices which are widely used among the students can be used in education and it can be considered as motivational tool for the learners. Mobile devices can be used for multi-tasking purpose such as recording notes in the form of audio or text, taking photos, creating, editing and publishing writing English language materials for the ESL learners. It also stated in this study that using MALL may bring constraint however, it has been concluded here that it could bring more benefits that constrain. Thus, the mobile device is a convenient tool to be used by students if it is used in an effective and productive manner.

A recent quantitative study conducted by (John Gyang Chaka, 2017) supports the idea thatmobile phone is a good teaching aid in learning. This is a study carried out on the perception and readiness of college students towards mobile learning in Nigeria. The education system in this country is a big challenge due to its extreme growth of its population, ethno-religious crisis and some terrorism activities. Therefore, this study was conducted to ease the learning process through mobile learning. The researcher carried out a study based on the Unified Theory of Acceptance and Use of Technology (UTAUT) involving 320 students from three colleges of education. The findings concluded that students in the education college supported the idea of mobile learning because it is useful and eases them in accessibility to learning process.

Another study on the use of mobile devices was conducted by (Nadire Cavus, 2016) to teach children's stories for the English as second language user. This was an experimental study to find out the potential of using the interactive mobile application in enhancing the learning skills such as listening, comprehension, pronunciation and vocabulary of these second language learners without the guidance of the teacher. The results of the study clearly indicated improvement in all the skills mentioned by the experimental group. Therefore, this study suggests that young children who are interested in improving these four skills listening, comprehension, pronunciation and vocabulary should find that the mobile application would be an enjoyable and useful tool to learn language. This finding is very much appropriate to the Dale's cone of learning where all the four skills are included in the pyramid (figure 1) and it will be effective if the learning process reaches the bottom of the pyramid. Another study of teaching ESL academic the potential of mobile learning was highlighted. In this study (Arlina Ahmad Zaki, 2015) touches in the integration of mobile technology in academic writing as she claims that there aren't many studies conducted but based on the findings it is believed that this mobile technology can benefit the process of teaching and learning. The mobile learning motivates the educators and learners to use mobile applications due to its accessibility, mobility and privacy as well. It also promotes self-directed learning as it can provide spontaneous and immediate information to bring up for discussion. In another word, mobile learning can be as a very interactive tool for learning.

A study done by (Mehrak Rahimi, 2014) investigated on the impact of the mobile dictionary on 34 lower-intermediate language learners and proved that mobile phone is considered as valuable learning tools in language learning as the experimental group of 17 people who used the online dictionary in the mobile phone and outperformed the 17 students from control group who used the printed dictionary. The findings showed that the EFL students who used the mobile dictionary to learn the English as Foreign Language improved their language ability compared to those who used printed dictionary. It is also mentioned that using mobile dictionaries helps learners acquire vocabulary and it is time efficient too. This experimental study (B.T Wang, 2015) used iPad as a mobile technology tool to facilitate the learning of English vocabulary. The classes were divided into two groups which are the experimental and the control group, the experimental group uses the iPad and the control group uses the semantic-map method to teach vocabulary. At the end of the semester, the group with the iPad vocabulary teaching instruction performed better in the post-test than the group who uses semantic-map. Besides that, the findings also indicate that the learners agreed on the use of technology in the classroom as it helps the learners in learning language, increases the students' learning motivation and enhances their learning outcome too. The researcher believes that using iPad app in teaching English vocabulary has positive effects on the students.

Another study of metanalysis done by (Yao-Ting Sung, 2015) on the effects of Learning languages with mobile devices revealed that by integrating mobiles in teaching and learning method it produced better learning achievements. It 
is also mentioned that using mobile devices for mixed language skills or vocabulary produced better learning effect than for single skills such as reading and writing. For the L2 learners using mobiles produce better achievement too.

The Malaysian government is moving towards the $21^{\text {st }}$ Century Learning and using technology in the education system. The current generation who is known as overcome this should see the most convenient and latest device that a student would have and carry with them frequently so that it can be used for the learning purpose. This is one of the challenges that need to be handled by the teachers in Malaysia as it is mentioned in the $21^{\text {st }}$ Century education challenges. Students are no more into the 'chalk and talk' teaching style instead they want to explore. Students should be encouraged to surf the internet for good purpose in learning and to find the latest information (SISC(+), 2016). Based on all the above studies done by the researchers, using mobile technology in learning a language gives a lot of benefits and will actually enhance the learning. The mobile phone will be an appropriate device to be used as a pedagogical tool because of its ability to retrieve information at anywhere anytime.

All the above studies have proven that the use of technology and mobile learning enhances the students' language and enables a learner to capture language in a rapid manner. It's also mentioned in the past studies that technology is a motivational tool for language enhancement It is believed that if the Ministry of Education of Malaysia would integrate technology as mentioned in the transformation plan, it will lead them to acquire the English language faster and fulfill one of the 6 keys attributes needed for a student as in the Malaysia Education Blueprint 2013-2025.

\section{Methodology / Materials}

\subsection{Research Respondents and Setting}

This study uses the quantitative approach. The purpose of this experimental study is to investigate on the effectiveness of using mobile phone as a tool for learning vocabulary compared to the conventional way of using a dictionary for English as a Second Language (ESL). The subjects for this study were 50 form 5 arts students (23 male and 27 female) of 17 years old from a public school in a state of Selangor, Malaysia. They were chosen out of 156 form 5 arts students from the school. The respondents were chosen based on their quick placement test consisting of 50 questions testing on their grammar and vocabulary ability. The selected students' marks ranged from 32-39 points. This is to determine which level they are in and to make sure all chosen respondents are in the same level of the language ability. (Kerr) This placement test results suggest the level of vocabulary be given to the students for the experimental study too. The outcome recommended upper intermediate test.

\subsection{Instruments}

The type of instruments used here is subject completed instrument - achievement test to measure an individual's knowledge or skill in a given subject. They are mostly given in schools to measure learning or the effectiveness of instructions (Jack R.Fraenkel, 2012). Two instruments were used in this study: a pre-test and a post-test on choosing the correct synonym. The words in the pre-test and the post test will not be the same because the pre-test answers could influence the choice of answer in the post-test as they already looked and found the correct meaning of the words in the dictionary. This is to make sure on the validity of the answers in the post-test. The vocabulary test consists of 50 multiple choice questions (MCQ) of synonym and is answered within 60 minutes. The mobile phone with internet access and the printed Oxford Dictionary (Wehmeir, 2002) from the library was used to look for the answers. The test was scored out of 50 .

\subsection{Data Collection and Analysis}

The data needed will be the score of the pre-test and the post-test. The selected respondents were given a pre-test on the language ability by giving them the placement test before they were chosen to be the respondents. The respondents will be given a short 20 minutes briefing on how to use the printed dictionary to look for word meaning. Then they will go through the pre-test in the library where the same referential material (the printed dictionary) will be given to all the students. Time allocation for the test is 60 minutes. Test papers will be collected after one hour. The score of the pre-test will be recorded. After 3 days, the same students will be called for another vocabulary test, which is similar to the earlier test but different words were given. Time allocation for the test is 60 minutes. Test papers will be collected after one hour. The score of the post-test will be recorded. All the data scores will be analyzed by using excel program to get frequency of the score in the form histogram and line chart.

\section{Results and Findings}

The findings are presented in three sections. First, figure 1- bar chart describes the individual score of the student that is followed by figure 2- line chart to give a clearer picture on the achievement, which is then followed by figure 3 , describing the mark range frequency of using dictionary. Figure 4 describes the mark range frequency of using mobile phone. The last two figures ,Figure 5 and figure 6, describe the number of questions unanswered within the time allocated -1 hour, for both pre-test and post-test. 


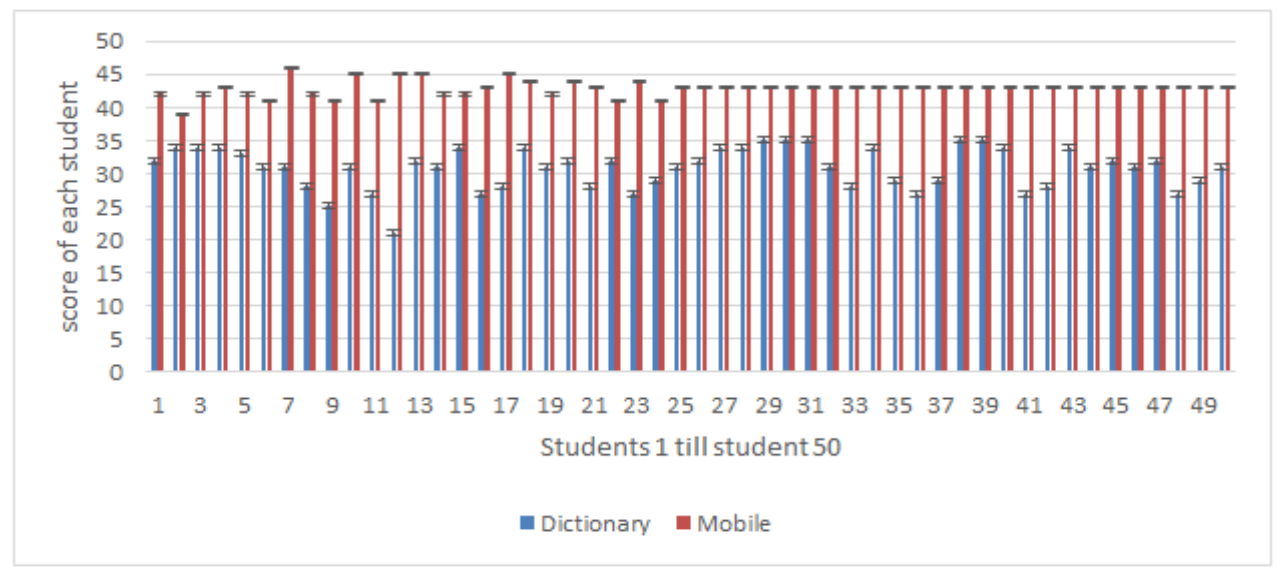

Figure 2. Individual score use of dictionary and mobile phone

Based on the figure above it is very noticeable that the score of every students using mobile phone is higher than the score of students using printed dictionary.

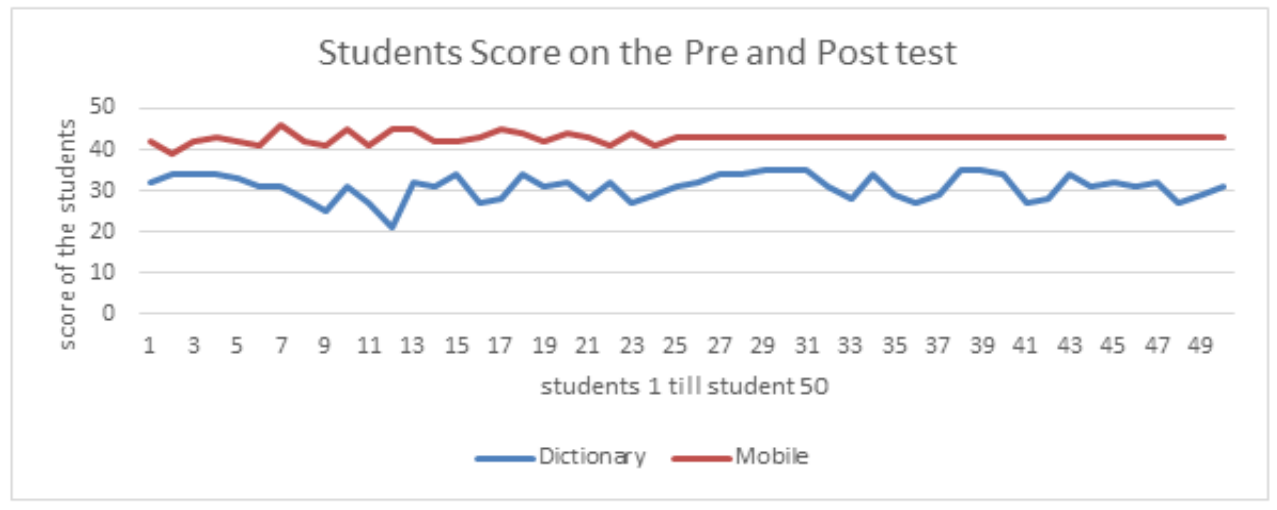

Figure 3. Comparison of achievement of score using of dictionary and mobile phone

Based on the line chart figure 3, the major score of students using mobile phone is higher 40 marks but the score of students using dictionary is in the range of 20 to 35. This clearly shows good achievement of scores in the post-test who uses mobile phone as the tool to search for the word.

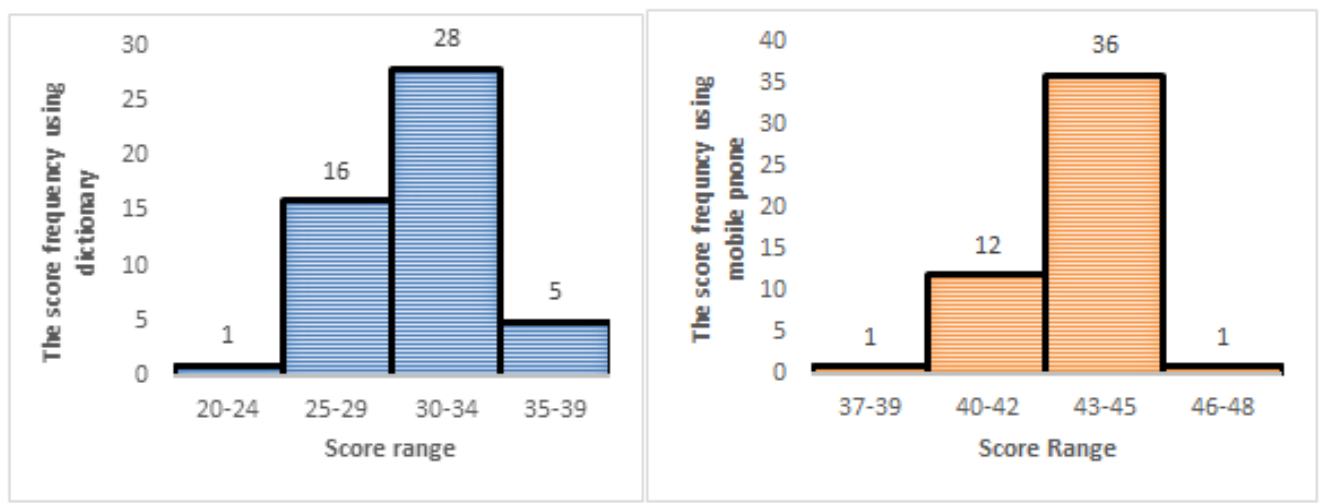

Figure 4. The comparison on the frequency of mark range for dictionary and mobile phone

The above charts show two different score range for the use of dictionary and use of mobile phone. Both charts show the highest frequency of score is more than $50 \%$ and the lowest frequency of score is only $2 \%$ but it differs in the range of the marks. The highest score frequency for dictionary is 30 to 34 and the highest score frequency for mobile phone is $43-45$. In another word it can be concluded that the mobile phone user scored better marks in the post-test. However, further analysis was done on the reason why the mobile phone user can score better than dictionary user in figure 5. 




Figure 5. The comparison on the frequency of unanswered questions for dictionary and mobile phone

The time allocated for the pre-test and the post is 1 hour for 50 multiple choice questions.

The charts in figure 5 show that the frequency of unanswered question - using dictionary ranging from 10- 20 questions with the highest frequency of 14 questions by 16 students. The frequency of unanswered question - using mobile phone ranging from 0 - 3 questions with the highest frequency of 31 students has answered all the questions. This is due to the time pressure.

\section{Conclusions}

The finding of this study reported that integrating technology via mobile phone is very beneficial to the Second Language learners because learning words via mobile phone is much faster than the conventional way; the printed dictionary. Everything appears on screen of the mobile phone when the students key in the words they are looking for. The mobile phone will also enable the students to do advance search on the usage of the word, origin of the word, images and the pronunciation. The students will also be able to listen to the pronunciation of the word but use dictionary and it is impossible for the students to say the pronunciation because the pronunciation or the words in the dictionary is written in the form of phonetic symbols.

Students are able to learn and improve their vocabulary knowledge using the internet resources which are searchable or browsable at any point of time. It can list words with an explanation of where they came from and when they were first used and even the real coloured picture or images of it to give the students better understanding of the words. In conclusion the adoptation of mobile phone usage as a pedagogical tool will surely enhance the learning and teaching process. With a nearly unlimited number of websites dealing with different aspects of language learning, this would be a very good way of learning a specific section of language such as vocabulary. However, this could only be done with internet access to the mobile phone and the readiness of teachers who are still unprepared and sceptical of students bringing mobile phones to the school. The management of school should plan a way to allow the students to bring the mobile phones to school for learning purpose with a few restrictions so that mobile phones are not misused but they are used wisely and productively to gain knowledge.

\section{REFERENCES}

[1] (KPM)., K. P. (2019, April 3). ICT Transformation Plan for the Ministry of Educatio, 2019-2013. Retrieved from Portal Rasmi Kementerian Pendidikan Malaysia: https://www.moe.gov.my/index.php/menumedia/media-cetak /penerbitan

[2] Arlina Ahmad Zaki, M. M. (2015). Potential of Mobile Learning in Teaching of ESL Academic Writing. 8(6), 11-19. doi:10.5539/elt.v8n6p11

[3] B.T Wang, C. T. (2015, February). Using ipad to facilitate English Vocabulary Learning. International Journal of Information and Education Technology, 5(2).

[4] Dorothy Chun, B. S. (2016). Technology in Language Use, Language Teaching, and Language Learning. The Modern Language Journal, 61-80. doi:10.1111/modl.12302

[5] Fetylyana Nor Pazilah, H. H. (2018). Using Infographics as a technology-based tool to develop 21st Century skills in an ESL context. Journal of Educational and Learning Studies, 35-38. doi:10.32698/0242

[6] Foundation, W. (2018, July 31). Cone of Experience - Edgar Dale (1969). Retrieved April 18, 2019, from https://en.wikipedia.org/wiki/Edgar_Dale.

[7] Foundation, W. (2019, January 30). Mobile Assisted Language Learning (MALL). Retrieved Aprl 18, 2019, from Wikipedia: https://en.wikipedia.org/wiki/Mobile-assisted_language_lear ning

[8] Giselle Tsirulnik. (n.d.). Mobile phone ranked most used electronic device: Forrester. Retrieved from https://www.mobilemarketer.com/ex/mobilemarketer/cms/ne ws/research/7473.html 
[9] Harwati Hashim, M. M. (2017). Mobile-assisted Language Learning (MALL) for ESL Learners : A review of Affordances and Constraints. Sains Humanika, 9, 45-50. doi:e-ISSN ISSN: 2289-6996

[10] Jack R.Fraenkel, N. E. (2012). How to Design and Evaluate Research in Education (8th ed.). New York, America: McGraw-Hill.

[11] John Gyang Chaka, I. G. (2017, February). Student's Perception and Readiness Towards Mobile Learning in Colleges of Education: a Nigerian Perspective. South African Journal of Education, 37(1), 12 pages. doi:10.15700/saje.v37n1a1282

[12] Kerr, P. (n.d.). Mc Millan Straight Forward, 2nd. Retrieved from Staraight Forward: http://www.macmillanstraightforwa rd.com/resources/tests

[13] Krashen, S. D. (1989). Principles and Practice in Second Language Acquisition (1982 ed.). University of Southern California, California, USA: Pergamon Press Inc. Retrieved April 14, 2019

[14] Malaysia, M. o. (2013). Malaysia Education Blueprint 2013-2015 (Preschool to Post- Secondary Education). Putrajaya, Malaysia.

[15] Maslawati M., F. M. (2014). Improving Undergraduates' Critique Via Computer Mediated. The Turkish Online Journal of Educational Technology, 13(3), 88-95

[16] Mehrak Rahimi, S. S. (2014). The Impact of Mobile Dictionary Use on Language Learning. International Conference on Current Trends in ELT (pp. 1469-1474). Tehran, Iran: Elsevier Ltd. doi:10.1016/j.sbspro.201403.567

[17] Ministry of Education, Malaysia. (2018). The Roadmap 2015-2025 (2nd Edition ed.). Putrajaya, Malaysia: Ministry of Education, Malaysia

[18] Nadire Cavus, D. I. (2016). Learning English using Children's Stories in Mobile Devices. British Journal of Educational Technology. doi:10.1111/bjet.12427

[19] Pendidikan, B. T. (2019, April 18). 1BestariNet. Retrieved April 18, 2019, from http://btp.moe.gov.my/1bestarinet: http://btp.moe.gov.my/1bestarinet

[20] SISC(+), P. H. (2016). Modul Pelaksanaan Pembelajaran Abad ke -21. Kajang, Selangor, Mlaysia: School of Improvement Specialist Coach Plus (SISC+). Retrieved March 15, 2019

[21] Wan Ummu Aiman Wan Azli, P. M. (2018, Jan 31). Perception on the Usage of Mobile Assisted Language Learning(MALL) in English as a Second Language (ESL) Learning among Vocational College Students. Creative Education, 9, 84-98. Retrieved from http://doi.org/10.4236/ce2018.91008

[22] Wehmeir, S. (2002). Oxford Advanced Learner's Dictionary -International Student's edition. UK: Oxford University Press

[23] Yao-Ting Sung, K.-E. C.-M. (2015). How Effective are Mobile Devices for Language Learning? A Meta Analysis. Educational Research Review. doi:10.10106/j.edurev.2015.09.001 